Check for updates

The BMJ

Cite this as: BMJ 2021;374:n2297

http://dx.doi.org/10.1136/bmi.n2297

Published: 17 September 2021

\section{Covid-19: Booster dose reduces infections and severe illness in over 60 s, Israeli study reports}

\section{Elisabeth Mahase}

Rates of infection and of severe illness were substantially lower in people aged over 60 who received a booster (third) dose of the Pfizer-BioNTech covid-19 vaccine than in those who had only two doses, Israeli researchers have reported.

Using the Israeli Ministry of Health database (for 30 July to 31 August 2021), the researchers extracted data on more than 1.1 million people aged 60 or over who had been fully vaccinated at least five months earlier. They compared the incidence of confirmed covid-19 and severe illness in people who had received the booster dose at least 12 days earlier with the rates in people who had not received a booster.

In the paper, published in the New England Journal of Medicine, the researchers reported that at least 12 days after the booster dose the rate of confirmed infection was lower in the booster group than in the non-booster group by a factor of 11.3 ( $95 \%$ confidence interval 10.4 to 12.3 ).

The rate of severe illness was also lower in the booster group, by a factor of 19.5 (12.9 to 29.5 ). The absolute difference between the groups in the rate of severe illness was 7.5 cases per 100 ooo person-days.

Furthermore, in a secondary analysis the researchers found that the rate of confirmed infection at least 12 days after the booster vaccination was lower than the rate after 4-6 days by a factor of 5.4 (4.8 to 6.1).

The authors wrote, "Even under this conservative analysis, the demonstrated rate reduction highlights the important role that a booster dose could play in mitigating the effects of waning immunity and immune evasion, especially during the emergence of variants of concern, such as the delta variant."

The study's limitations included that it did not consider differences in coexisting illnesses or the time interval between the first two doses, and that the follow-up period was short.

Commenting on the research, Peter English, a retired consultant in communicable disease control and former editor of Vaccines in Practice, said, "These are spectacularly good results, which are likely to have a very significant effect on the direct risk to individuals who receive a booster dose."

However, he added that because the UK generally used a longer dose interval between the first two doses (three months versus three weeks), which research indicated could result in increased efficacy, the UK may not see as big an improvement with booster doses as seen in Israel. "But even if the effect of giving a booster dose of vaccine is not as good as this paper found it to be in Israel, they could be extremely beneficial here in the UK," English said.
In the UK 30 million people from the highest risk groups are set to be offered booster jabs, with the government's vaccination advisory committee saying that the decision was "precautionary" and that on balance it was preferable to maintain a high level of protection among vulnerable adults throughout winter. ${ }^{2}$

This was despite other experts, including the developers of the Oxford-AstraZeneca vaccine Sarah Gilbert and Andrew Pollard, saying that boosters were not needed because immunity was lasting well. They have called for these vaccine doses to go towards vaccinating people around the world who are yet to have a single dose. ${ }^{3}$ Currently, $43 \%$ of the world's population has received at least one dose of a covid-19 vaccine. ${ }^{4}$

The World Health Organization called for a moratorium on boosters until at least the end of September, to enable a minimum of $10 \%$ of the population of every country to be vaccinated. Its director general, Tedros Adhanom Ghebreyesus, said in a speech on 4 August, "We cannot accept countries that have already used most of the global supply of vaccines using even more of it, while the world's most vulnerable people remain unprotected." 5

Bar-On YM, Goldberg Y, Mandel M, et al. Protection of BNT162b2 Vaccine Booster against Covid-19 in Israel. 2021. doi: 10.1056/NEJMoa2114255.

2 Wise J. Covid-19: Booster doses to be offered to 30 million people in UK. BMJ 2021;374:n2261. doi: 10.1136/bmj.n2261 pmid: 34521637

3 Mahase E. Covid-19: Third vaccine dose boosts immune response but may not be needed, say researchers. BMJ 2021;373:n1659. doi: 10.1136/bmi.n1659 pmid: 34187780

4 Coronavirus (covid-19) vaccinations. Our World in Data. https://ourworldindata.org/covid-vaccinations.

5 Taylor L. Covid-19: WHO calls for booster shot ban until end of September. BMJ 2021;374:n1962. doi: 10.1136/bmj.n1962 pmid: 34353851

This article is made freely available for use in accordance with BMJ's website terms and conditions for the duration of the covid-19 pandemic or until otherwise determined by BMJ. You may use, download and print the article for any lawful, non-commercial purpose (including text and data mining) provided that all copyright notices and trade marks are retained. 